\title{
Abrasive wear behaviour of conventional and large-particle tungsten carbide-based cermet coatings as a function of abrasive size and type
}

\author{
Z. Kamdi ${ }^{1 *}$, P.H. Shipway ${ }^{1}$, K.T. Voisey ${ }^{1}$ and A.J. Sturgeon ${ }^{2}$ \\ ${ }^{1}$ Division of Materials, Mechanics and Structures, Faculty of Engineering, \\ The University of Nottingham, University Park, Nottingham NG7 2RD, UK \\ ${ }^{2}$ Genesis Oil and Gas Consultants Ltd. London, UK
}

Received Date Line

\begin{abstract}
Abrasive wear behaviour of materials can be assessed using a wide variety of testing methods, and the relative performance of materials will tend to depend upon the testing procedure employed. In this work, two cermet type coatings have been examined, namely (i) a conventional tungsten carbide-cobalt thermally sprayed coating with a carbide size of between $\sim 0.3-5 \mu \mathrm{m}$ and (ii) a tungsten carbide-nickel alloy weld overlay with large spherical carbides of the order of $\sim 50-$ $140 \mu \mathrm{m}$ in diameter (DuraStell). The wear behaviour of these two materials has been examined by the use of two abrasion tests, namely the micro-scale abrasion test using both silica and alumina abrasives (typically 2-10 $\mu \mathrm{m}$ in size), and the dry sand-rubber wheel test (ASTM G65), again with both silica and alumina abrasives (typically $180-300 \mu \mathrm{m}$ in size). It was found that when the abrasive particles were of the same scale or larger than the mean free path between the hard phase particles, then the matrix phase was well protected by the hard phases. Testing (in both test types) with alumina abrasives resulted in wear of both the hard carbide phases and the matrix phases in both the thermally sprayed coating and the weld overlay, with the thermally sprayed coating exhibiting lower wear rates. The wear behaviour of the materials with the more industrially relevant silica abrasive was more complex; the thermally sprayed coating exhibited a lower wear rate than the weld overlay with the fine abrasive in the micro-scale abrasion test due to effective shielding of the matrix from abrasive action due to the fine reinforcement particle size. In contrast, with the coarser silica abrasive in the dry sand-rubber wheel test, the weld overlay with the large carbides was able to provide matrix protection with low rates of wear, whereas the thermally sprayed coating wore by fracture of the more brittle microstructure. These findings demonstrate the importance of selection of appropriate laboratory test procedures and abrasives to simulate behaviour of materials in service environments.
\end{abstract}

Keyword: hardmetal, dry sand-rubber wheel, micro-scale abrasion, WC-Co, ASTM G65

\footnotetext{
${ }^{*}$ Corresponding author. Tel.: +44 115 8466407; fax: +44 1159513764.

E-mail address: emxzk@nottingham.ac.uk (Z. Kamdi)
} 


\section{Introduction}

Material removal caused by hard particles in lateral motion across a surface is known as abrasive wear [1]. According to Eyre [2], 50\% of wear in industry is caused by abrasion, and as such, much laboratory work has been carried out to understand wear behaviour in wide range of materials with wear tests such as the dry sandrubber wheel test, the micro-scale abrasion test and the pin-on-drum sliding abrasion test. Hutchings [3] described two broad mechanisms of abrasive wear, dominated by plastic deformation and brittle fracture respectively. Twobody and three-body are distinct terms used in describing the mode of abrasive wear; in two-body abrasion, abrasive particles move across the surface but are constrained not to rotate whereas in three-body abrasion, the abrasive particles are free to rotate. Three-body abrasion is generally encountered when the abrasive moves freely between two opposed surfaces in relative motion [1,3]. In wear tests with loose abrasive particles, the abrasive is normally a third body between two surfaces (one of these being the testpiece) but the particles can either groove across the testpiece (being temporarily embedded in the counterbody) or roll across the surface, depending upon the conditions of the test and the materials being abraded [4, 5]. Thus, as suggested by Trezona et al. [6], the terms "grooving" and "rolling" will be used to describe abrasive motion.

Micro-scale abrasion is a technique that is gaining wide acceptance for the wear testing of coatings and surface engineered materials [7]. This test allows the abrasion behaviour of a small sample to be examined, and allows the controlled use of fine abrasive particles in a slurry [8]. In addition, it also allows the wear behaviour of thin coatings and layers to be studied independently of the influence of the underlying material [9]. Much previous work has studied the effect of test parameters including ball type [10], slurry concentration [11-13], abrasive angularity [14], load $[13,15]$ and abrasive type $[13,16,17]$. The test is commonly used with abrasives in the size range $2 \mu \mathrm{m}$ to $10 \mu \mathrm{m}$, but larger abrasives $(\sim 250-300 \mu \mathrm{m})$ have also been used [18]. However, three-body abrasion testing with abrasives in this larger size range is more commonly conducted with the dry sand-rubber wheel (DSRW) test. The DSRW test simulates low stress three-body wear which typically occurs in a range of industrial applications such as linkages, pivot pins and wire ropes in the mining industry. Both the micro-scale abrasion test and the DSRW test are thus used in this study to understand the effect of test type (and particularly abrasive size and type) on wear behaviour.

Much work on characterizing the wear properties of hardmetal and cermet coatings has been conducted. The main parameters influencing the properties of such coatings are carbide grain size, carbide volume fraction and binder mean free path $[19,20]$. The abrasive wear rate is found to increase with increasing carbide grain size when examined with abrasive that is slightly larger than the carbide itself [21-24]. A study on the addition of WC to a nickel-based coating demonstrated that increasing the carbide content resulted in a decrease in the wear rate as the carbide prevented abrasive penetration into the surface [25]. Van Acker et al. [26] conducted abrasion tests on a nickel alloy reinforced with much larger carbides (between $30 \mu \mathrm{m}$ to $150 \mu \mathrm{m}$ ) and observed preferential wear of the nickel alloy surrounding the WC particles, but with no significant dependence of wear rate on the carbide particle size. Neville et al. [27] studied the erosion-corrosion performance of a $65 \mathrm{wt} \%$ carbide reinforced nickel- 
self fluxing alloy with four different carbide sizes ranging from $45 \mu \mathrm{m}$ to $180 \mu \mathrm{m}$. As binder extrusion dominated the erosion behaviour, the material with the larger carbide exhibited the highest erosion-corrosion rate since this material exhibited the highest binder mean free path.

In the current work, the wear behaviour of two carbide-reinforced materials with very different microstructural scales was examined. The materials were a WC-Co thermally sprayed coating (carbide size $\sim 0.3-$ $5 \mu \mathrm{m})$ and a weld overlay coating with much larger carbide size $(\sim 50-140 \mu \mathrm{m})$. The abrasion behaviour of these materials was examined using abrasive particles also with very different scales $(180-300 \mu \mathrm{m}$ in the DSRW test and $2-10 \mu \mathrm{m}$ in the micro-scale abrasion test), with two abrasive types with very different levels of hardness (alumina and silica).

\section{EXPERIMENTAL PROCEDURE}

\subsection{Materials properties}

The wear behaviour of two types of WC-based coatings has been examined using both the micro-scale abrasion test and the DSRW abrasion test; in addition, mild steel has been included in the testing programme as a reference material. The compositions of the coating feedstock are $\mathrm{WC}-17 \mathrm{wt} \% \mathrm{Co}$ and $\mathrm{W}_{\mathrm{x}} \mathrm{C}-35 \mathrm{wt} \% \mathrm{Ni}$ alloy. Both coatings were prepared and supplied by external vendors; the thermally sprayed WC-Co coating (hereafter termed TSWC) was deposited by high velocity oxy-fuel (HVOF) spraying, and the $\mathrm{W}_{\mathrm{x}} \mathrm{C}-35 \mathrm{wt} \% \mathrm{Ni}$ alloy was weld deposited, being marketed under the name DuraStell (Deloro Stellite, UK). The coatings have been characterised using a Philips XL30 scanning electron microscope (SEM) and a Siemens D500 X-ray diffractometer (XRD). Vickers hardness tests were carried out using a Mitutoyo microhardness tester (with a 300 gf load). For each sample type, ten indentations were made from which the average hardness was calculated. All indentation tests were performed on samples which had been ground and finally polished with $1 \mu \mathrm{m}$ diamond abrasive. The volume fraction of the carbide in each of the deposits has been determined using quantitative analysis of backscattered electron images produced via SEM at magnifications which allowed the carbide particles to be readily measured.

\subsection{Wear testing}

\subsubsection{Micro- scale abrasion test}

Micro-scale abrasion testing was performed using a block-on-ball geometry with a commercially available apparatus, the TE66 Micro-scale Abrasion Tester (Phoenix Tribology Ltd., UK). A schematic diagram of the apparatus is shown in Fig. 1. In this test, the sample is loaded against the ball (using a dead-weight); the ball is rotated about a horizontal axis parallel to the plane of the specimen surface while abrasive slurry is dripped onto the ball and specimen resulting in wear of the specimen. Specimen wear results in an indentation, which generally takes the form of a spherical cap with geometry similar to that of the ball. The samples were tested at a range of sliding distances up to $80 \mathrm{~m}$ with a constant load of $0.2 \mathrm{~N}$. In order to ensure reproducibility, tests at each sliding 
distance were performed three times. Following a wear test, the sample was removed from the apparatus and the wear crater dimensions measured using a Talysurf CLI 1000 profilometer (Taylor Hobson Ltd., UK). The scars were traversed using a contact probe with spacing of data points of $1 \mu \mathrm{m}$ in the scan direction and with a $10 \mu \mathrm{m}$ spacing between adjacent traverses. Mountains Software (Digital Surf, France) was used to analyse the data, from which the wear crater volume was deduced.

Micro-scale abrasion tests were conducted with slurries of two abrasive types suspended in distilled water: (i) alumina (White bauxilite micropowder, F1200, USF Abrasive Developments Ltd., UK) and (ii) silica (Sibelco UK Ltd.), with nominal sizes ranging from 2 to $10 \mu \mathrm{m}$. SEM micrographs showing the abrasive morphologies are shown in Fig. 2 In each test, the slurry was kept agitated with a magnetic stirrer. Different solids volume fractions are used in the two slurries, namely 17.2 vol\% and $30 \mathrm{vol} \%$ for alumina and silica respectively. The solids fraction in the alumina slurry was in line with that used in previous work [16]; however, it was found that if the same solids fraction was used for the silica slurry, then a slurry of very low viscosity was produced which resulted in ridge formation in the wear scars (the presence of such ridges is known to invalidate the tests) [13]. As such, the solids volume fraction in the silica slurry was increased to equalise their dynamic viscosities $(0.02 \pm 0.001 \mathrm{~Pa} \mathrm{~s}$ measured over a 2 minute period with a Bohlin Rheometer fitted with $30 \mathrm{~mm}$ diameter, conically ended cylinder producing a nominal shear rate of $118 \mathrm{~s}^{-1}$ ). The hardness of the abrasives could not be measured due to their small

size; typical hardnesses quoted for silica and alumina abrasives are 750-1200 and 1800-2000 $\mathrm{kgf} \mathrm{mm}^{-2}$, respectively [3].

Bearing steel (52100) balls, with a diameter of $25.4 \mathrm{~mm}$ (supplied by Dejay Distribution Ltd., UK), were employed as the counterfaces. Each ball was used for many tests and was turned after each test (to ensure use of a new circumferential track); each track on the ball was run-in with silicon carbide abrasive slurry for 200 revolutions under standard test conditions before being utilised in testing to ensure that its surface was reproducible and roughened to promote abrasive particle entrainment [10]. Examination of the wear scars following testing was made by SEM employing secondary electron imaging.

\subsubsection{Dry sand-rubber wheel abrasion test}

The DSRW test is based on the ASTM G65 standard [28]. A schematic diagram of this block-on-wheel apparatus is shown in Fig. 3, based on a modified design reported by Stevenson and Hutchings [29] (the wearing face of the specimen is horizontal in the current design whereas it is in the vertical plane in the original ASTM G65 standard). The rubber tyre has an external diameter of $227 \mathrm{~mm}$, is $12.7 \mathrm{~mm}$ wide and $10 \mathrm{~mm}$ thick and is rotated with speed of $195 \mathrm{rpm}$, equivalent to a contact sliding speed of $2.32 \mathrm{~m} \mathrm{~s}^{-1}$. The abrasive is introduced onto the rubber wheel just before the contact region between the test specimen and the wheel. The average feed rates were $2.50 \mathrm{~g} \mathrm{~s}^{-1}$ and $2.23 \mathrm{~g} \mathrm{~s}^{-1}$ for the alumina and silica abrasives respectively. The nominal particle size for silica ranged from $180 \mu \mathrm{m}$ to $250 \mu \mathrm{m}$ and for alumina ranged from $212 \mu \mathrm{m}$ to $300 \mu \mathrm{m}$. SEM images showing the morphology of the abrasives are presented in Fig. 2, where it can be seen that the silica has a rounded morphology whilst the alumina is an angular abrasive. In the tests, a static applied load of $50 \mathrm{~N}$ load was employed. The mass 
of the sample was measured before and after every 780 wheel revolutions to a maximum of 3900 revolutions ( $5560 \mathrm{~m}$ of abrasion). The gravimetric wear rate is taken as the gradient of the steady-state section of the plot of mass loss versus abrasion distance. This is converted to a volumetric mass loss through a knowledge of the density of the material being abraded; this was derived from both mass loss and volume loss measurements of individual wear scars following abrasion with alumina, the latter measurement being made using profilometry as indicated in Section 2.2.1. In addition, a single line profile along the length of the wear scar was made for each material-abrasive combination using the Taylsurf CLI 1000 profilometer. A Philips XL30 SEM was employed utilising secondary electron (SE) imaging to examine the morphology of the worn surfaces.

\section{Results}

\subsection{Materials Characterisation}

The TSWC coating is made up of small angular carbides with dimensions up to $5 \mu \mathrm{m}$ embedded in an amorphous matrix phase which is made up of cobalt with some tungsten and carbon dissolved in it [30]; the coating exhibits a significant level of porosity (Fig. 4a). The DuraStell weld overlay coating (Fig. 4b) can be seen to contain significantly larger spherical carbides with diameters of up to $140 \mu \mathrm{m}$. In addition, small precipitates are distributed homogenously in the binder. From image analysis, the volume fraction of the carbide phases were measured as 56 and 59 vol\% for the TSWC and DuraStell coatings respectively.

Average hardness values for the coatings are shown in Table 1. It can be seen that the average hardness data for the DuraStell has a very wide spread associated with the two phases, the scale of which leads to some indentations being clearly contained in either the carbides alone or the matrix alone, whilst others resulted in the indentation crossing the boundary between carbide and matrix. The use of an average hardness takes into account not only the hardness of the individual phases, but also their volume fraction. Indentations which occurred solely in either the carbide or matrix phases individually were separated and the hardness values of the individual phases derived from these are also reported in Table 1. The average carbide hardness lies between those reported in the literature for WC $\left(\sim 2200 \mathrm{kgf} \mathrm{mm}^{-2}\right)$ and for $\mathrm{W}_{2} \mathrm{C}\left(\sim 2700 \mathrm{kgf} \mathrm{mm}^{-2}[31]\right)$; it has been previously shown that the large carbides in DuraStell are a mix of $\mathrm{WC}$ and $\mathrm{W}_{2} \mathrm{C}[32]$.

\subsection{Micro-scale abrasion}

Fig. 5a shows the development of wear volume with abrasion distance for some typical examples of materials in the micro-scale abrasion test, namely both the TSWC and DuraStell coatings abraded with silica slurry. Even in these cases (the two cases with the lowest total wear volume), the wear volume was observed to be approximately proportional to the abrasion distance, which is in accord with the general model of abrasion. The wear rate was taken as the gradient of the best fit line passing through the data.

As seen in Fig. 5b, both coatings show significantly lower wear rates than mild steel abraded under similar conditions. For each material type, the wear rate with alumina abrasive was greater than with the silica abrasive. 
The wear rate of DuraStell was approximately 1.5 times that of the TSWC with alumina abrasive, but was more than ten times that of the TSWC when abraded with silica.

Fig. 6 shows the central regions of the wear scars from all samples and Fig. 7 shows profilometer traces of the depth of material removal across the wear scar in all cases. No clear directionality is seen in the wear scar of mild steel following alumina abrasion, indicating particle rolling through the contact (Fig. 6). In the wear scar in mild steel following silica abrasion, grooving is seen. No grooving on the scale of the abrasive particles is observed for abrasion of either coating type with either the silica or alumina abrasives. Preferential binder removal is clearly seen in the TSWC coating following abrasion with both abrasive types, but with alumina abrasion, rounding of the carbide particles is more apparent when compared to that observed following silica abrasion. Fig. 7 indicates that the silica abrasive has not removed any significant depth of material from the surface of the TSWC, whereas a wear depth of $\sim 7 \mu \mathrm{m}$ is observed following abrasion with alumina.

With both alumina and silica slurries, binder phase removal of the DuraStell has taken place via particle rolling (although some deep abrasive channelling is observed in the wear scar following silica abrasion). In both cases, damage to the carbides can be seen. Fig. 7 shows that the carbide particles in DuraStell abraded with alumina have been worn, but that they stand proud of the surrounding matrix phase which is worn preferentially. However, it is not clear that the carbide particles have been significantly worn by the silica abrasive (their height has not changed significantly from the original surface height) and that the wear of the matrix phase may thus not proceed further.

\subsection{Dry sand-rubber wheel (DSRW)abrasion}

Fig. 8a shows the development of wear volume with abrasion distance for some typical examples of materials in the DSRW abrasion test, namely both the TSWC and DuraStell coatings abraded with silica. Even in these cases (the two cases with the lowest total wear volume), the wear volume was observed to be approximately proportional to the abrasion distance, which is in accord with the general model of abrasion. The wear rate was taken as the gradient of the best fit line passing through the data.

Both coatings exhibit significantly lower wear rates than mild steel (see Fig. 8b). In each case, the wear rate for abrasion with alumina is higher than the wear rate with silica. DuraStell has the lowest wear rate for silica abrasion whereas the TSWC coating has the lowest wear rate for alumina abrasion.

From the secondary electron images of the wear scars shown in Fig. 9, rolling abrasion can be seen for mild steel with both abrasive types. Less damage (approximately an eighth) is seen following silica abrasion compared to abrasion with alumina, since, whilst both abrasive particles are hard compared to the mild steel, the silica has a rounded morphology whereas the alumina has a more aggressive angular morphology.

Fig. 9 shows that abrasion with alumina has resulted in recession of the binder phase and carbides phases at approximately the same rate in the TSWC coating; however, abrasion with silica has resulted in preferential removal of the binder phase, leaving the carbide particles standing proud of the surface. Some fracture damage to the carbides can be observed following abrasion with silica. Fig. 10 shows that both the alumina and silica 
abrasives result in significant material removal $(\sim 115 \mu \mathrm{m}$ and $70 \mu \mathrm{m}$ respectively). The smooth surface morphology of the alumina-abraded TSWC indicates that material removal takes place through cutting wear, whereas the surface of the silica abraded TSWC indicates that material removal occurs by carbide fracture and loss.

For the DuraStell coating, binder wear through rolling indentation of abrasive particles can be seen following tests with both abrasives (Fig. 9). Clear carbide damage was observed following abrasion with alumina, but this was not seen following silica abrasion. Fig. 10 shows that the DuraStell coating has been significantly worn by abrasion with alumina, with depths of wear of $\sim 240 \mu \mathrm{m}$. The profilometer trace indicates that the carbides are standing proud of the background matrix phase (due to their lower rates of wear) but that they are being worn down. In contrast, Fig. 10 indicates that the silica abrasive has not been able to produce any significant wear in the abrasion of the carbide particles in DuraStell, and while background matrix phase wear has been observed, this is not expected to develop significantly as the carbides will protect the metallic matrix from further damage.

\section{Discussion}

There are a number of features observed in the results which have been reported many times in other pieces of published work, such as the fact that the abrasion rate of the carbide reinforced materials is much lower in abrasion than that of mild steel, and that abrasion with relatively soft, rounded silica results in much lower wear rates than abrasion with hard, angular alumina. In light of this, this discussion will focus on the dependence of the abrasion rates and mechanisms on the scale of the microstructural features of the two carbide reinforced materials compared to the scale of the abrasive particles themselves, and how this is affected by the properties of the abrasive particles.

\subsection{Micro-scale abrasion testing}

Alumina has been used widely as an abrasive in micro-scale abrasion testing. With a similar hardness to the carbide particles themselves in both the TSWC coating and the DuraStell weld overlay, alumina was able to abrade the carbides; Fig. 6 shows clear damage to the carbides in both materials, and Fig. 7 shows significant recession of the wear surfaces below the original surface. The small distance between the carbides in the TSWC coating (Fig. 6) will mean that the matrix phase is protected from direct abrasion until the carbide particles themselves have been worn away. The large distance between the carbide particles in the DuraStell coating is not able to prevent independent abrasion of the matrix in this case, and it is observed that the overall wear rate of the DuraStell is higher than that of the TSWC coating. Van Acker et al. [26] conducted microscale abrasion tests of large carbide reinforced materials (similar to DuraStell), but again saw little benefit of the large carbide size due to the very hard nature of the abrasive used ( $\mathrm{SiC}$ was used in their tests) and the large mean free path between the carbide particles. 
Fig. 5 indicates that the wear rates of the carbide reinforced materials with silica abrasive are much lower than those of the mild steel; specifically, whilst the wear rates of both coating types with alumina abrasive are an order of magnitude less than that of the mild steel, as is the wear rate of DuraStell with silica abrasive, the wear rate of the TSWC coating with silica abrasive is more than two orders of magnitude less than that with mild steel. This finding is in accord with that of Gates et al. [33], where it is suggested that the greatest benefits of harder materials in conferring low rates of abrasive wear is seen as the abrasive particles themselves become softer, as the softer abrasives are less able to damage the harder test materials. For the TSWC coating abraded with silica, the hard carbide phase is abraded only at a very low rate by the abrasive and the binder phase is protected from contact with the abrasive by the small mean free path between the carbide particles themselves; accordingly, very little damage is observed for this combination (Fig. 7). In the case of the DuraStell weld overlay, the silica abrasive was able to attack the relatively soft metallic binder phase independently, due to the high mean free path between the carbides, resulting in recession of the binder surface (Fig. 7). As such, the lowest rates of abrasive wear in the micro-scale test are observed when the mean free-path between the carbides is of the same order of magnitude or less than that of the scale of the abrasives. A similar reduction in wear rate in micro-scale abrasion of sintered WC-Co hardmetals with increasing fineness of the carbide phase (and the associated reduction in mean free path between the carbides) has been seen previously [16]. Also, the lowest wear rates are observed when the matrix is geometrically well protected from abrasion by the carbides (due to the low mean free path between the carbides in comparison to the abrasive size) and when the carbides themselves are most resistant to wear, which is the case for the softer silica abrasive.

\subsection{DSRW abrasion testing}

Fig. 8 shows that the wear rates of the carbide reinforced materials are around an order of magnitude lower than those of mild steel for abrasion with both alumina and silica abrasives.

In the abrasion of the TSWC coating, the abrasive particles are much larger than the scale of the reinforcing carbide size, and thus the materials wear in a homogeneous fashion. The alumina abrasive is hard enough to cause ductile (ploughing) abrasion of the material as a whole. However, despite the silica abrasive being significantly softer then the TSWC coating, the wear rate is only decreased to half of that observed with the alumina abrasive (Fig. 8). With silica abrasion, the cracking of individual carbides can be observed (Fig. 9) and it has been previously shown that thermally sprayed materials of this type can abrade via intersplat cracking. These damage mechanisms were not observed in the micro-scale abrasion test due to both the much lower applied loads and the far larger number of particles in the contact in that test (due to the fine particle size), both of which result in a low load per particle. Cracking will tend to be promoted by high loads per particle and thus these mechanisms result in wear of the TSWC coating, even with the soft silica abrasive. Similar arguments have been proposed for the effect of abrasive particle size in erosion of large carbide reinforced materials by Neville et al. [27]. As such, for the TSWC coating, despite it having a hardness which should result in very low abrasion rates, material removal is promoted via material cracking, indicating that this is toughness controlled. The relatively low toughness of these materials is associated with the mechanisms of formation of the coatings as follows; (i) the binder phase is less 
tough than a normal metallic binder since it generally consists of a relatively hard amorphous phase [20]; (ii) fracture is observed along intersplat boundaries [20]; (iii) the carbide particles themselves are damaged during the spraying process since impact typically occurs at speeds of around $600 \mathrm{~m} \mathrm{~s}^{-1}$ [34].

The behaviour of the DuraStell coating in abrasion with large particles is in contrast to when abraded in the micro-scale abrasion test. Here, the scale of the abrasives is not smaller than the mean free path between the carbide particles, which promotes protection of the matrix by the hard carbides. The wear rate of the DuraStell with hard alumina abrasives is around twice that of the TSWC coating; Fig. 9 shows attack of the carbide particles themselves during wear (with signs of fracture on the surfaces of the carbides being evident). Fig. 10 shows that the wear surface has proceeded to depths far beyond those of individual carbide particles, indicating that the carbides are not able to resist abrasion with alumina. However, the wear rate of DuraStell with silica abrasives in this test is around half that of the TSWC coating (Fig. 8). Fig. 9 shows that the carbide particles have not been significantly damaged by the abrasion with silica, due to the softness of the silica. Fig. 10 shows that, overall, the wear surface has not proceeded significantly below that of the original surface, although some matrix phase wear has occurred. The scale of the carbide particles themselves has prevented their pullout, and thus has resulted in an abrasion resistant material. The fracture damage mechanisms that were observed to operate with the TSWC coating are not operative for this material, and the absence of these is again associated with the fabrication of the deposits; in this case (an unlike the TSWC coating), the binder phase is ductile (and not a brittle amorphous phase), there are no splat boundaries, and the carbide particles themselves are not mechanically damaged by impact during the deposition process.

\section{Conclusions}

In this work, the behaviour of two very different wear resistant hard coatings were examined in abrasion with both large and small abrasive particles, and with soft and hard abrasive particles. The rates of wear of these materials were typically an order of magnitude less than those of mild steel tested under identical conditions, except in the case of the TSWC coating abraded with silica in the micro-scale abrasion test where the hardness of all the phases in the material prevented wear by ductile indentation and ploughing and the applied loads per particle were not enough to cause fracture at any scale in the coating.

It has been found that wear behaviour of such composite materials is controlled by a number of features. The relative scale of the microstructural constituents compared to the scale of the abrasive particles governs whether the composite properties of the material dictate the wear behaviour, or whether the wear behaviour of the individual phases will govern the overall development of wear. Wear behaviour is also controlled by the abrasive hardness; hard alumina abrasive was able to cause wear of both materials in both abrasion tests examined, removing material from the carbides by plastic flow and (in some cases) fracture. With the more industrially relevant silica abrasive, the TSWC coating exhibited the lowest wear rate in micro-scale abrasion since the mean free path between the hard phases was such that abrasion of the binder phase between the carbides was precluded. In the DSRW test with silica abrasive, the carbides in the DuraStell coating were able to provide enough protection to the matrix. Moreover, the carbides themselves were harder than the abrasive and thus resisted wear 
by ductile ploughing, and the microstructure as a whole (including the carbides) showed no evidence of brittle failure under the abrasive action of the particles. In contrast, the TSWC coating, whilst hard, exhibited abrasion by brittle fracture, resulting in an abrasion rate twice that of the DuraStell coating. As such, it is critical to consider all the mechanisms by which failure can occur in abrasion and to select coatings to best avoid undesirable failure mechanisms.

\section{Acknowledgement}

The authors would like to thank Deloro Stellite, Swindon, UK for provision of coated samples.

\section{References}

1. Axén, N., S. Jacobson, and S. Hogmark, Influence of hardness of the counterbody in three-body abrasive wear - an overlooked hardness effect, Tribology International 27 (1994) 233-241

2. $\quad$ Eyre, T.S., Wear characteristic of metals, Tribology International 10 (1976) 203-212

3. Hutchings, I.M., Tribology Friction and Wear of Engineering Materials. London: Edward Arnold. 1992 p. 82-86, 137-138, 141-171.

4. Nahvi, S.M., P.H. Shipway, and D.G. McCartney, Particle motion and modes of wear in the dry sandrubber wheel abrasion test, Wear 267 (2009) 2083-2091

5. Shipway, P.H., A mechanical model for particle motion in the micro-scale abrasion wear test, Wear 257 (2004) 984-991

6. Trezona, R.I., D.N. Allsopp, and I.M. Hutching, Transition between two-body and three-body abrasive wear: influence of test condition in the micro-scale abrasive wear test, Wear 225-229 (1999) 205-214

7. $\quad$ Gee, M.G., The Use of PC Scanners in Micro-abrasion Wear testing, Wear 259 (2005) 1448-1452

8. Rutherford, K.L. and I.M. Hutchings, A Micro-abrasive Wear Test, With Particular Application to Coated System, Surface \& Coatings Technology 79 (1996) 231 - 239

9. Ibáñez, M.J., J. Gilabert, M. Vicent, P. Gómez, and D. Muñoz, Determination of The Wear Resistance of Traditional Ceramic Materials by Means of Micro-abrasion Technique, Wear 267 (2009) 2048-2054

10. Allsopp, D.N., R.I. Trezona, and I.M. Hutching, The Effects of Ball Surface Condition in The Microscale Abrasive Wear Condition, Tribology Letters 5 (1998) 259-264

11. Trezona, R.I., D.N. Allsopp, and I.M. Hutchings, Three-body abrasive wear testing of soft materials, Wear 233-235 (1999) 209-221

12. Bello, J.O., R.J.K. Wood, and J.A. Wharton, Synergistic effects of micro-abrasion-corrosion of UNS S30403, S31603 and S32760 stainless steel, Wear 263 (2007) 149-159

13. Shipway, P.H. and C.J.B. Hodge, Microabrasion of glass - the critical role of ridge formation, Wear 237 (2000) 90-97

14. Stachowiak, G.B. and G.W. Stachowiak, The effects of particle characteristics on three-body abrasive wear, Wear 249 (2001) 201-207

15. Bose, K. and R.J.K. Wood, Influence of Load and Speed on Rolling Micro-abrasion of CVD Diamond and Other Hard Coatings, Diamond and Related Materials 12 (2003) 753-756

16. Shipway, P.H. and J.J. Hogg, Dependence of Microscale Abrasion Mechanisms of WC-Co Hardmetals on Abrasive Type, Wear 259 (2005) 44 - 51

17. Shipway, P.H. and J.J. Hogg, Wear of Bulk Ceramics in Micro-scale Abrasion - The Role of Abrasive Shape and Hardness and Its Relevance to Testing of Ceramic Coatings, Wear 263 (2007) 887 - 895

18. Stachowiak, G.B., G.W. Stachowiak, and J.M. Brandt, Ball-cratering abrasion test with large abrasive particle, Tribology International 39 (2006) 1-11

19. Guilemany, J.M., J.M. Miguel, S. Vizcaino, and F. Climent, Role of three-body abrasion wear in the sliding wear behaviour of WC-Co coatings obtained by thermal spraying, Surface \& Coatings Technology 140 (2001) 141-146

20. Stewart, D.A., P.H. Shipway, and D.G. McCartney, Abrasive wear behaviour of conventional and nanocomposite HVOF-sprayed WC-Co coatings, Wear 225-229 (1999) 789-798 
21. Baldoni, J.G., S.F. Wayne, and S.T. Buljan, Cutting Tool Materials: Mechanical Properties - Wear Resistance Relationships, ASLE Trans. (1986) 347-352

22. Wayne, S.F., J.G. Baldoni, and S.T. Buljan, Abrasion and Erosion of WC-Co with Controlled Microstructures, Tribology Trans. 33 (1990) 611-617

23. O'Quigley, D.G.F., S. Luyckx, and M.N. James, An Emperical Ranking of a Wide Range of WC-Co Grades in Terms of Their Abrasion Resistance Measured by ASTM Standard B611-85 Test, International Journal of Refractory Metals and Hard Materials 14 (1997) 73-79

24. Scieska, S.F. and K. Filipowics, An Intergrated Testing Methods for Cermet Abrasion Resistance and Fracture Toughness Evaluation, Wear 216 (1998) 202-212

25. Wang, H., W. Xia, and Y. Jin, A study on abrasive resistance of Ni-based coatings with a WC hard phase, Wear 195 (1996) 47-52

26. Acker, K.V., D. Vanhoyweghen, R. Persoons, and J. Vangrunderbeek, Influence of Tungsten Carbide Particles Size and Distribution on Wear Resistance of Laser Clad WC/Ni Coatings, Wear 258 (2005) 194-202

27. Neville, A., F. Reza, S. Chiovelli, and T. Revega, Erosion-corrosion behaviour of WC-based MMCs in Liquid-solid slurries, Wear 259 (2005) 181-195

28. Standard test method for measuring abrasion using the dry sand / rubber wheel apparatus ASTM, G6504, 2004

29. Stevenson, A.N.J. and I.M. Hutchings, Development of the Dry Sand/rubber Wheel Abrasion Test, Wear 195 (1996) 232-240

30. Stewart, D.A., P.H. Shipway, and D.G. McCartney, Microstructural evolution in thermally sprayed WCCo coatings: comparison between nanocomposite and conventional starting powders, Acta Materialia 48 (2000) 1593-1604

31. $\quad$ McColm, I.J., Ceramic Hardness. New York: Plenum Press. 1990 p. 302.

32. Kamdi, Z., P.H. Shipway, K.T. Voisey, and A.J. Sturgeon. Micro-scale abrasion behaviour of conventional and large-particle cermet coatings for hard chrome replacement. in 14th Nordic Symposium on Tribology -Nordtrib 2010. Lulea, Sweden: (2010).

33. Gates, J.D., M.S. Dargusch, J.J.Walsh, S.L. Field, M.J.P. Hermand, B.G. Delaup, and J.R. Saad, Effect of abrasive mineral on alloy performance in the ball mill abrasion test, Wear 265 (2008) 865-870

34. Sudaprasert, T., P.H. Shipway, and D.G. McCartney, Sliding behaviour of HVOF sprayed WC-Co coatings deposited with both gas-fuelled and liquid-fuelled systems, Wear 255 (2003) 943-949 


\section{Figure captions}

Fig. 1: Schematic diagram of the micro-scale abrasion apparatus

Fig. 2: Morphology of the abrasives used in the test programme; (a) silica for micro-scale abrasion; (b) alumina for micro-scale abrasion; (c) silica for DSRW abrasion; (d) alumina for DSRW abrasion.

Fig. 3: Schematic diagram of the DSRW abrasive wear test apparatus

Fig. 4: SEM-BSE images of cross sections of (a) TSWC coating and (b) DuraStell weld overlay

Fig. 5: (a) Wear volume in micro-scale abrasion as a function of abrasion distance for both TSWC and DuraStell with silica slurry; (b) Wear rate in micro-scale abrasion of mild steel (MS), DuraStell and TSWC with alumina and silica slurries

Fig. 6: Central regions of wear scars following $80 \mathrm{~m}$ of micro-scale abrasion with both alumina and silica slurries

Fig. 7: Profilometer traces across the centre of wear scars following $80 \mathrm{~m}$ of micro-scale abrasion for the two materials examined, each with both silica and alumina abrasive slurries.

Fig. 8: (a) Wear volume in DSRW abrasion as a function of abrasion distance for both TSWC and DuraStell with silica abrasive; (b) Wear rate in DSRW abrasion of mild steel (MS), DuraStell and TSWC with alumina and silica abrasives

Fig. 9: Central regions of wear scars following $5560 \mathrm{~m}$ of DSRW abrasion with both alumina and silica abrasives

Fig. 10: Profilometer traces across the centre of wear scars following $5560 \mathrm{~m}$ of DSRW abrasion for the two materials examined, each with both silica and alumina abrasives.

Table 1: Measured characteristics of the two coating types 